\title{
ANALISIS DATA SEISMIK REFRAKSI DENGAN METODE GENERALIZED-RECIPROCAL
}

\author{
Ashadi Salim \\ Mathematics \& Statistics Department, School of Computer Science, Binus University \\ Jln. K.H. Syahdan no. 9, Palmerah, Jakarta Barat 11480 \\ ashadisalim@binus.ac.id
}

\begin{abstract}
The analysis of seismic refraction data by the generalized reciprocal method can be used for delineating undulating refractors. The forward and reverse times of arrival at different geophones with XY distance along a refraction profile, are used for calculating time depth. The seismic wave velocity in refractor may be obtained from velocity analysis function, and the depth of refractor under each geophone is obtained from time-depths function. This method has been applied at one line of seismic refraction measurement that was $440 \mathrm{~m}$ long with 45 geophone positions. The measurement obtained $20 \mathrm{~m}$ as the optimum XY-value and $2250 \mathrm{~m} / \mathrm{s}$ as the velocity of seismic wave in refractor, and the undulating refractor topography with the depths varies 10.4 - $22.1 \mathrm{~m}$. The optimum XY-value was obtained from approximate calculation derived from the observation, that was indicated the absent of undetected layer.
\end{abstract}

Keywords: seismic refraction, undulating refractor, velocity analysis function, time depth function

\begin{abstract}
ABSTRAK
Analisis data seismik refraksi dengan metode "Generalized Reciprocal" dapat digunakan untuk memperoleh gambaran topografi dari refraktor berundulasi. Waktu kedatangan gelombang dari "forward dan reverse" pada beberapa posisi geofon yang berjarak XY sepanjang lintasan pengukuran seismik refraksi, digunakan untuk menghitung fungsi analisis kecepatan dan "time depth". Kecepatan gelombang seismik pada refraktor dapat diperoleh dari fungsi analisis kecepatan, dan kedalaman refraktor diperoleh dari fungsi "time depth". Metode ini telah digunakan pada satu lintasan pengukuran seismik refraksi yang panjang lintasannya $440 \mathrm{~m}$ dengan 45 posisi geofon. Dari hasil pengukuran diperoleh bahwa harga XY otimumt adalah $20 \mathrm{~m}$, kecepatan gelombang seismik pada refraktor adalah $2300 \mathrm{~m} / \mathrm{s}$, dan topografi refraktor berundulasi dengan kedalaman bervariasi antara 10,4-22,1 m. Jarak XY optimum hasil perhitungan mendekati sama dengan jarak XY optimum hasil observasi. Hal ini mengindikasikan bahwa tidak terdapat lapisan yang tidak terdeteksi sepanjang lintasan pengukuran seismik.
\end{abstract}

Kata kunci: seismik refraksi, refraktor berundulasi, fungsi analisis kecepatan, fungsi time depth 


\section{PENDAHULUAN}

Analisis atau interpretasi data seismik refraksi dengan metode "intercept time" atau metode T$\mathrm{X}$, menggunakan anggapan bahwa refraktor (bidang batas antara dua lapisan batuan berurutan) merupakan suatu bidang datar. Dalam kenyataan di lapangan hal tersebut jarang ditemukan, di mana umumnya bidang batas antara dua lapisan batuan adalah tidak rata atau berundulasi. Beberapa metode untuk analisis data seismik refraksi untuk bidang refraktor yang berundulasi sudah banyak dikembangkan (Palmer, 1980, 1981; Whiteley and Ecceleston, 2006), di antaranya: metode "Delay Time", metode "Plus-Minus", dan metode Hagiwara - Masuda

Pada makalah ini dikemukan pemakaian metode "Generalized-Reciprocal" dalam menganalisis /interpretasi data seismik refraksi untuk refraktor berundulasi. Metode ini didasarkan pada pengukuran waktu kedatangan gelombang "forward" dan "reverse" pada beberapa geofon yang berjarak $X Y$ sepanjang lintasan pengukuran seismik, serta pengukuran waktu timbal balik dari perambatan gelombang antara dua titik sumber, di mana hasil pengukuran waktu tersebut digunakan untuk menghitung fungsi analisis kecepatan dan "time depth". Kecepatan gelombang pada refraktor dan kedalaman rafraktor di bawah setiap posisi geofon dapat dihitung tanpa mengetahui informasi detail lapisan-lapisan di atas bidang refraktor. Grafik fungsi analisis kecepatan untuk beberapa jarak $\mathrm{X}-\mathrm{Y}$ dapat digunakan untuk identifikasi ada atau tidaknya suatu patahan dalam daerah penelitian. Keuntungan lainya dari metoda ini, dapat digunakan untuk mengetahui adanya lapisan tidak terdeteksi (hidden layer), baik berupa suatu lapisan tipis maupun lapisan inverse (kecepatan gelombang pada suatu lapisan lebih rendah dari lapisan batuan di atasnya, yaitu dengan membandingkan harga X-Y optimum hasil observasi dengan yang diperoleh dari hasil perhitungan (Palmer,1980; Hatherly and Nevill, 1986).

\section{METODE}

\section{Persamaan Waktu Perambatan Gelombang}

Pada gambar 1 ditunjukan perambatan gekombang refraksi untuk model 4 lapisan batuan (Palmer, 1980). Waktu perambatan gelombang dari A ke B yang melalui bidang refraktor ke-3 adalah:

$$
t_{A B}=\sum_{j=1}^{3}\left(Z_{j A} \operatorname{Cos} \alpha_{j 4}+Z_{j B} \operatorname{Cos} \beta_{j 4}\right) / N_{j}+A B \operatorname{Cos} \theta_{1} \operatorname{Cos}\left(\theta_{2}-\theta_{1}\right) \operatorname{Cos}\left(\theta_{3}-\theta_{2}\right) / N_{4}
$$

di mana:

$\mathrm{Z}_{\mathrm{jA}}$ : tebal lapisan ke $\mathrm{j}$ di bawah titik $\mathrm{A}$

$\mathrm{Z}_{\mathrm{jB}}$ : tebal lapisan ke $\mathrm{j}$ di bawah titik $\mathrm{B}$

$\theta_{1}, \theta_{2}$ dan $\theta_{3}$ berturut-turut merupakan sudut bidang bias ke 1, 2 dan 3 terhadap permukaan

$\mathrm{V}_{1}, \mathrm{~V}_{2}, \mathrm{~V}_{3}$ dan $\mathrm{V}_{4}$ berturut-turut merupakan kecepatan rambat gelombang pada lapisan ke 1, 2, 3 dan 4

$\alpha_{j 4}$ adalah sudut bias kritis lapisan ke $\mathrm{j}$ terhadap lapisan ke 4 di bawah titik $\mathrm{A}$

dan $\beta_{\mathrm{j} 4}$ di bawah titik B 


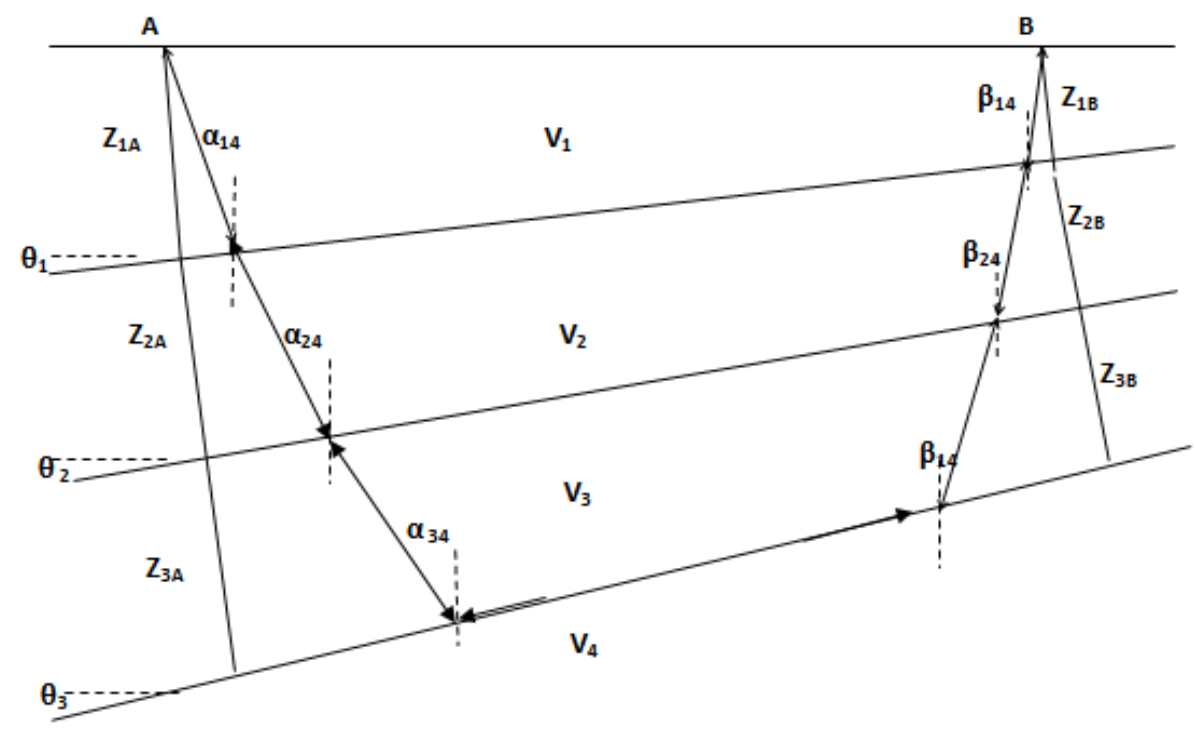

Gambar 1. Model 4 lapisan untuk menurunkan persamaan waktu perambatan gelombang dari titi A ke titik B (Palmer, 1980).

Pengembangan persamaan (1) di atas untuk model $n$ lapisan:

$$
t_{A B}=\sum_{j=1}^{n-1}\left(Z_{j A} \operatorname{Cos}_{j n}+Z_{j B} \operatorname{Cos} \beta_{j n}\right) / V_{j}+A B \operatorname{Cos} \theta_{1} \operatorname{Cos}\left(\theta_{2}-\theta_{1}\right) \ldots \operatorname{Cos}\left(\theta_{n-1}-\theta_{n-2}\right) / V_{n}
$$

\section{Menentukan Kecepatan Rambat Gelombang pada Bidang Refraktor}

Fungsi analisis kecepatan untuk titik $\mathrm{G}$ yang berada di tengah antara titik $X$ dan $Y$, seperti ditunjukan pada Gambar 2 (didefinisikan sebagai berikut:

$$
t_{V}=\left(t_{A Y}-t_{B X}+t_{A B}\right) / 2
$$

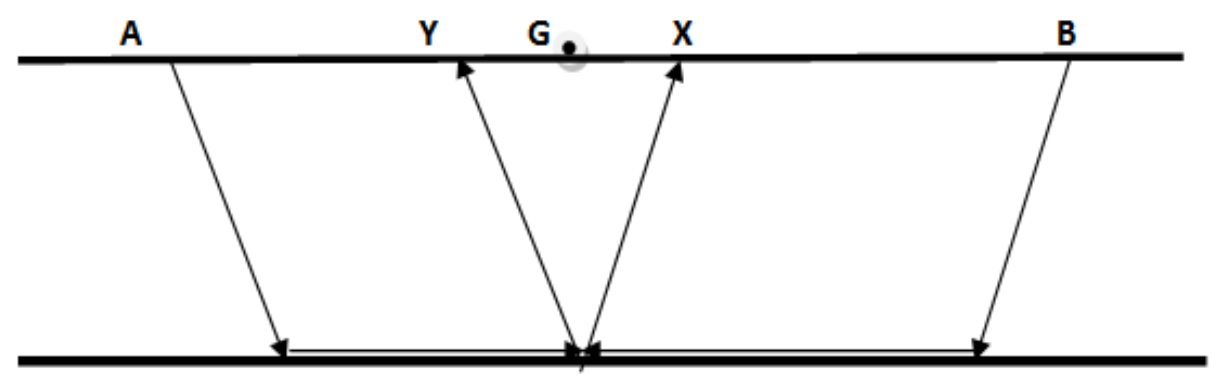

Gambar 2. Geometri Pendefinisian Fungsi Analisis Kecepatan (Palmer, 1980; Hatherly et al, 1986).

Kecepatan semu gelombang pada bidang refraktor ke $n\left(\mathrm{~V}^{\prime}{ }_{\mathrm{n}}\right)$ diperoleh dari kemiringan (slope) grafik $t_{\mathrm{V}}$ vs $\mathrm{AG}$, yaitu:

$$
1 / \mathrm{V}_{\mathrm{n}}=\mathrm{dt}_{\mathrm{V}} / \mathrm{dx}
$$

Dalam praktek, harga $V_{n}^{\prime}$ umumnya dianggap sebagai kecepatan gelombang sesungguhnya pada bidang refraktor ke $n\left(V_{n}\right)$. Untuk mendapatkan ketelitian $V_{n}$ yang paling baik, grafik $t_{V}$ vs $A G$ 
dibuat untuk beberapa harga $X Y$, dan grafiknya yang paling mendekati garis lurus, yang disebut sebagai $X Y$ optimum), akan memberikan harga $V_{n}$ dengan ketelitian yang paling baik. Pada $X Y$ optimum diasumsikan bahwa gelombang dari sumber di A ke titik $X$ dan gelombang dari sumber di B ke titik $Y$ berasal dari titik yang sama pada bidang refraktor (Palmer, 1980; Orlowsky et al, 1988; Whiteley et al 2006,).

\section{Menentukan Kedalaman Bidang Refraktor}

Kedalaman bidang refraktor di bawah setiap posisi geofon dapat dihitung dengan menghitung terlebih dahulu waktu perambatan gelombang ke setiap geofon (time depth) menggunakan persamaan berikut (Palmer, 1980, 1981):

$$
\mathrm{t}_{\mathrm{G}}=\left\{\mathrm{t}_{\mathrm{AY}}+\mathrm{t}_{\mathrm{BX}}-\left(\mathrm{t}_{\mathrm{AB}}+X Y / \mathrm{V}^{\prime} \mathrm{n}\right)\right\} / 2
$$

$V^{\prime} n$ diperoleh dari persamaan (4).

Dengan merubah $t_{\mathrm{AY}}, t_{\mathrm{BX}}$ dan $t_{\mathrm{AB}}$ seperti dalam bentuk persamaan (2) dan kemudian disubsitusikan ke persamaan 5, akan diperoleh:

$$
t_{G}=\sum_{j=1}^{n-1}\left(Z_{j G}\left(\operatorname{Cos} \alpha_{j n}+\operatorname{Cos} \beta_{j n}\right) /\left(2 V_{j n}\right)\right.
$$

dan dapat dinyatakan dalam bentuk persamaan:

$$
t_{G}=\sum_{j 1}^{n-1}\left(Z_{j G} N_{j n}\right)
$$

dengan:

$\mathrm{V}_{\mathrm{jn}}=2 \mathrm{Vj} /\left(\operatorname{Cos} \alpha_{\mathrm{jn}}+\operatorname{Cos} \beta_{\mathrm{jn}}\right)$

$Z_{j G}$ merupakan ketebalan lapisan ke j dibawah posisi geofon $(G)$

Persamaan (6) di atas menyatakan hubungan time depth dengan kedalaman.

Harga-harga $\alpha_{\mathrm{jn}}$ dan $\beta_{\mathrm{jn}}$ bergantung sudut-sudut kemiringan bidang refraktor, yang umumnya bervariasi secara acak, sehingga sulit untuk menentukan harga $V_{j n}$ sesungguhnya. Dengan mengabaikan sudut kemiringan tersebut, $\mathrm{V}_{\mathrm{jn}}$ dapat didekati dengan persamaan:

$$
\mathrm{V}_{\mathrm{jn}}=\mathrm{V}_{\mathrm{n}} \cdot \mathrm{V}_{\mathrm{jn}} /\left(\mathrm{V}_{\mathrm{n}}^{\prime 2}-V_{j}^{\prime 2}\right)^{1 / 2}
$$

Dengan pendekatan lapisan horizontal, persamaan (6) menjadi:

$$
\begin{array}{ll} 
& \mathrm{t}_{\mathrm{G}}=\sum_{\mathrm{j} 1}^{\mathrm{n}-1}\left(\mathrm{Z}_{\mathrm{jG}} \operatorname{Cosi}_{\mathrm{jn}}^{\prime} \mathrm{N}_{\mathrm{j}}^{\prime}\right) \\
\text { dan jarak XY optimum: } & \mathrm{XY}{ }_{\mathrm{opt}}=\sum_{\mathrm{j} 1}^{\mathrm{n}-1}\left(2 \mathrm{Z}_{\mathrm{jG}} \tan i_{j n}\right) \\
\text { dengan } & \left.\sin i_{j n}^{\prime}=\mathrm{V}_{\mathrm{j}}^{\prime} / \mathrm{V}_{\mathrm{n}}^{\prime}\right)
\end{array}
$$

Kedalaman bidang refraktor dapat dihitung dengan menggunakan kecepatan rata-rata pada lapisan-lapisan di atas refraktor, tanpa harus mendefinisikan semua lapisan. Dengan menggunakan notasi kecepatan rata-rata dan dengan $\sin \bar{i}=\overline{\mathrm{V}} / \mathrm{V}_{\mathrm{n}}^{\prime}$, persamaan time depth menjadi:

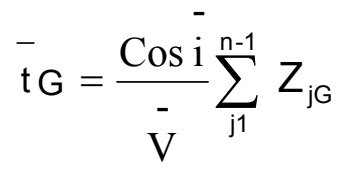


dan

$$
X Y_{\text {opt }}=2 \tan \bar{i} \sum_{j 1}^{n-1} Z_{j G}
$$

Dari kedua persamaan di atas dapat diperoleh:

$$
\overline{\mathrm{V}}=\left(\mathrm{V}_{\mathrm{n}}^{\prime 2} \mathrm{XY} /\left(2 \overline{\mathrm{t}}_{\mathrm{G}} \mathrm{V}_{\mathrm{n}}^{\prime}+\mathrm{XY}\right)\right)^{1 / 2}
$$

Dengan demikian kedalaman bidang refraktor dapat dihitung dengan persamaan:

$$
\sum_{j=1}^{n-1} Z_{j G}=\mathrm{t}_{\mathrm{G}} \overline{\mathrm{V}} / \operatorname{Cos} \overline{\mathrm{i}}=\mathrm{t}_{\mathrm{G}} \sqrt{\frac{\mathrm{V}_{\mathrm{n}}^{\prime} \mathrm{XY}}{2 \overline{\mathrm{t}}_{\mathrm{G}}}}
$$

Kedalaman bidang refraktor di bawah titik sumber (titik A dan B) dihitung menggunakan waktu "intercept time" dari fungsi analisis kecepatan, yaitu:

$$
\left(t_{\mathrm{V}}\right)_{X=0}=\sum_{\mathrm{j}=1}^{\mathrm{n}-1} \mathrm{Z}_{\mathrm{jP}} / \mathrm{V}_{\mathrm{jn}}
$$

Dan perhitungan tersebut dilakukan untuk fungsi analisis kecepatan dari "direct dan reverse shooting”

\section{HASIL DAN PEMBAHASAN}

Analisis data seismik refraksi dengan metoda Generalized Reciprocal ini telah diterapkan pada 1 lintasan pengukuran seismik refraksi, dengan panjang lintasan $440 \mathrm{~m}$. Lintasan pengukuran terdiri atas 2 segmen pengukuran dengan panjang setiap segmen $220 \mathrm{~m}$, dengan posisi geofon 1 dari segmen kedua berimpit dengan posisi geofon 23 segmen pertama. Pada setiap segmen dilakukan pengukuran secara timbal-balik (forward" dan "reverse" shooting) dan sumber jauh pada kedua sisi setiap segmen. Dengan teknik pengukuran yang dilakukan, memungkinkan untuk menggabungkan data pengukuran dari kedua segmen menjadi data satu lintasan pengukuran dengan 45 posisi geofon.

Jarak antara dua geofon yang berdekatan adalah $10 \mathrm{~m}$. Harga $t_{A B}$ diambil harga rata-rata dari hasil yang diperoleh sumber di A dan sumber di B.

Pada tabel 1 ditunjukan data hasil pengukuran (data gabungan dari kedua segmen pengukuran). berupa waktu perambatan gelombang refraksi dari sumber ke masing-masing geofon. data forward $\left(\mathrm{t}_{\mathrm{A}}\right)$ pada kolom 2 dan data reverse $\left(\mathrm{t}_{\mathrm{B}}\right)$ pada kolom 3. Gelombang yang datang pada

\begin{tabular}{|c|c|c|c|c|c|c|c|}
\hline $\begin{array}{l}\text { No. } \\
\text { Geofon }\end{array}$ & $\mathbf{T}_{\mathrm{A}}(\mathrm{ms})$ & $\mathrm{T}_{\mathrm{B}}(\mathrm{ms})$ & & $\mathbf{T}_{\mathrm{V}}(\mathrm{ms})$ & & $\mathrm{T}_{\mathrm{G}}(\mathrm{ms})$ & H(m) \\
\hline & & & $X Y=10 \mathrm{~m}$ & $X Y=20 \mathrm{~m}$ & $X Y=30 \mathrm{~m}$ & $X Y o p t=20 \mathrm{~m}$ & \\
\hline 1 & 25 & 221 & & & & & \\
\hline 2 & 30 & 218 & $\begin{array}{l}15.5 \\
18,5\end{array}$ & 17,0 & 18.0 & 11.6 & 17,0 \\
\hline 3 & 33 & 212 & 22,5 & 19,5 & 21.5 & 11.1 & 16,3 \\
\hline 4 & 35 & 207 & 27,0 & 24,5 & & 10.1 & 14,8 \\
\hline
\end{tabular}
masing-masing geofon tersebut dianggap merupakan gelombang refraksi dari refraktor yang dipelajari

Tabel 1

Data Pengukuran dan Hasil Interpretasi Seismik Refraksi 


\begin{tabular}{|c|c|c|c|c|c|c|c|}
\hline 5 & 39 & 201 & & 29,0 & & 9.6 & 14,1 \\
\hline \multirow{2}{*}{6} & 43 & 198 & 32,0 & 34,5 & 31.5 & 9.1 & 13,3 \\
\hline & & & 36,0 & & 37.0 & & \\
\hline \multirow[t]{2}{*}{7} & 48 & 191 & & 38,5 & & 10.1 & 14,8 \\
\hline & 53 & 186 & 42,0 & 45,0 & 41.5 & 9.6 & 14,1 \\
\hline 8 & & & 47,5 & & 46.5 & & \\
\hline \multirow[t]{2}{*}{9} & 59 & 181 & & 49,0 & & 8,6 & 12,6 \\
\hline & & & 51,5 & & 51.0 & & 118 \\
\hline 10 & 62 & 176 & 560 & 53,5 & 55.0 & 8,1 & 11,8 \\
\hline \multirow[t]{2}{*}{11} & 66 & 173 & & 57,5 & & 7,1 & 10,4 \\
\hline & & & 59,0 & & 61.0 & 91 & 133 \\
\hline 12 & 69 & 168 & 65,8 & 62,5 & 63,5 & 9,1 & 13,3 \\
\hline \multirow[t]{2}{*}{13} & 76 & 164 & & 66,0 & & 7,6 & 11,1 \\
\hline & 78 & 162 & 68,0 & 715 & 69,5 & 91 & 13.3 \\
\hline 14 & & & 72,5 & & 74,0 & & \\
\hline \multirow[t]{2}{*}{15} & 85 & 158 & & 75,0 & & 10,6 & 15,5 \\
\hline & & & 77,0 & & 78,0 & & \\
\hline \multirow[t]{2}{*}{16} & 90 & 152 & & 80,0 & & 11,6 & 17,0 \\
\hline & & & 83,0 & & 81,0 & & \\
\hline \multirow[t]{2}{*}{17} & 96 & 146 & & 84,0 & & 9,6 & 14,1 \\
\hline & 98 & & 87,0 & 89.5 & 86,5 & 9.1 & 13,3 \\
\hline 18 & & 142 & 91,5 & 89,3 & 91,5 & $, 4,1$ & 15, \\
\hline \multirow[t]{2}{*}{19} & 103 & 138 & & 93,5 & & 9,1 & 13,3 \\
\hline & & & 95,5 & & 95,5 & & \\
\hline \multirow[t]{2}{*}{20} & 107 & 134 & & 97,5 & & 9,1 & 13,3 \\
\hline & 111 & & 99,5 & 1025 & 100,5 & 101 & \\
\hline 21 & 111 & 131 & 104.0 & 102,5 & 104.5 & 10,1 & 14,8 \\
\hline \multirow[t]{2}{*}{22} & 117 & 128 & & 106,0 & & 10,6 & 15,5 \\
\hline & & & 107,5 & & 108,0 & & \\
\hline \multirow[t]{2}{*}{23} & 121 & 122 & & 109,5 & & 11,1 & 16,3 \\
\hline & & & 112,5 & & 111,0 & & \\
\hline 24 & 125 & 119 & 1155 & 114,0 & 1155 & 9,6 & 14,1 \\
\hline \multirow[t]{2}{*}{25} & 128 & 114 & J & 117,0 & J & 9,6 & 14,1 \\
\hline & & & 119,5 & & 120,0 & & \\
\hline \multirow[t]{2}{*}{26} & 131 & 110 & & 122,5 & & 10,1 & 14,8 \\
\hline & & & 124,5 & & 123,5 & & \\
\hline 27 & 137 & 104 & 1285 & 125,5 & 1290 & 9,1 & 13,3 \\
\hline 28 & 139 & 99 & & 132,0 & & 9,6 & 14,1 \\
\hline & & & 134,5 & & 134,5 & & \\
\hline 29 & 146 & 95 & & 137,0 & & 9,6 & 14,1 \\
\hline 30 & & & 139,0 & 1410 & 139,0 & & 141 \\
\hline 30 & 151 & 93 & 142,0 & 141,0 & 143,0 & 9,6 & 14,1 \\
\hline 31 & 155 & 86 & & 144,0 & & 10,6 & 15,5 \\
\hline & & & 147,5 & & 146,0 & & \\
\hline 32 & 159 & 83 & & 149,5 & & 9,1 & 13,3 \\
\hline 33 & 163 & & 151,0 & 1510 & 152,5 & & \\
\hline & 100 & ov & 155,5 & 154,0 & & 10,0 & \\
\hline
\end{tabular}




$\begin{array}{llllllll}34 & 169 & 74 & 157,5 & 159,5 & 11,1 & 16,3 \\ 35 & 173 & 70 & 160,5 & 162,5 & 166,5 & 10,1 & 14,8 \\ 36 & 177 & 64 & 164,5 & 168,0 & 170,5 & 11,6 & 17,0 \\ 37 & 184 & 61 & 175,0 & 173,5 & 175,0 & 11,1 & 16,3 \\ 38 & 189 & 59 & 177,5 & 176,5 & 180,0 & 11,1 & 16,3 \\ 39 & 192 & 55 & 183,0 & 181,0 & 184,5 & 13,6 & 19,9 \\ 40 & 199 & 49 & 189,0 & 186,5 & 188,5 & 15,1 & 22,1 \\ 41 & 206 & 47 & 192,5 & 191,5 & 193,5 & 14,1 & 20,7 \\ 42 & 210 & 43 & 19,5 & 194,5 & 196,5 & 15,1 & 22,1 \\ 43 & 214 & 35 & 196,5 & 198,5 & & 15,1 & 22,1 \\ 44 & 218 & 31 & 202,5 & 204,5 & 200,5 & 13,1 & 19,2 \\ 45 & 222 & 37 & 206,5 & & & & \end{array}$

Dengan menggunakan persamaan (3), dihitung fungsi analisis kecepatan $\left(t_{V}\right)$ untuk $X-Y 10 \mathrm{~m}$, $20 \mathrm{~m}$ dan $30 \mathrm{~m}$. Hasil perhitungan tersebut ditunjukan pada kolom 4, 5 dan 6 pada Tabel 1. Dari grafik $t_{V}$ Vs $A G$ (AG adalah jarak dari sumber ke geofon) untuk ketiga harga $X Y$ tersebut, diperoleh bahwa grafik untuk $X Y 20 \mathrm{~m}$ adalah paling mendekati garis lurus. Maka dari itu, harga $X Y 20 \mathrm{~m}$ tersebut diambil sebagai harga $X Y$ optimum. Dari grafik $t_{V}$ Vs $X Y$ untuk $X Y$ optimum tersebut, dihitung kecepatan semu gelombang pada bidang refraktor. Kecepatan semu pada refraktor tersebut besarnya adalah $2250 \mathrm{~m} / \mathrm{s}$.

Time depth $\left(t_{G}\right)$ untuk setiap posisi geofon dihitung dengan mnenggunakan persamaan (5), dan dilakukan untuk $X-Y=20 \mathrm{~m}$, hasil perhitungan tersebut ditunjukan pada kolom 7 Tabel 1 .

Selanjutnya dengan menggunakan persamaan (8) dapat dihitung kedalaman bidang refraktor di bawah posisi masing-masing geofon, dan hasil perhitungan tersebut ditunjukan pada kolom 8 Tabel 1.

Dari kolom 8 Tabel 1 di atas terlihat bahwa kedalaman bidang refraktor sepanjang lintasan pengukuran adalah bervariasi antara $10,4-22.1 \mathrm{~m}$. Hasil tersebut menunjukan bahwa topografi permukaan refraktor adalah tidak rata atau berundulasi, seperti ditunjukan poda Gambar 3.

Dengan menggunakan metode "intercept time" diperoleh bahwa di daerah penelitian terdapat tiga lapisan batuan, lapisan pertama dengan kecepatan rambat gelombang $670 \mathrm{~m} / \mathrm{s}$ dan tebal rata-rata di bawah titik sumber adalah $2 \mathrm{~m}$, serta lapisan kedua dengan kecepatan rata-rata $1350 \mathrm{~m} / \mathrm{s}$. Dari datadata tersebut dan dengan menggunakan persamaan (7), diperoleh $X Y$ opt $=21,2 \mathrm{~m}$. Harga ini adalah relatif sama dengan harga XYopt hasil observasi $(20 \mathrm{~m})$, dengan simpangan sebesar $6 \%$. Dari hasil tersebut, dapat diduga bahwa di sepanjang lintasan pengukuran tidak terdapat lapisan tidak terdeteksi.

Pada Gambar 3 ditunjukan penampang kecepatan hasil pengukuran seismik, yang menunjukan bahwa di daerah penelitian dapat diidentifikasikan tiga lapisan batuan. Setiap lapisan batuan didefinisikan berdasarkan kecepatan rambat gelombang pada masing-masing lapisan . Menurut data geologi daerah setempat, lapisan pertama dengan kecepatan gelombang $670 \mathrm{~m} / \mathrm{s}$ merupakan lapisan pasir lempungan, lapisan kedua dengan kecepatan gelombang $1350 \mathrm{~m} / \mathrm{s}$ merupakan lapisan lanau 
kerikilan dengan variasi perlapisan pasir lempungan, dan lapisan ketiga dengan kecepatan gelombang $2250 \mathrm{~m} / \mathrm{s}$ merupakan lapisan batuan andesit basaltik.

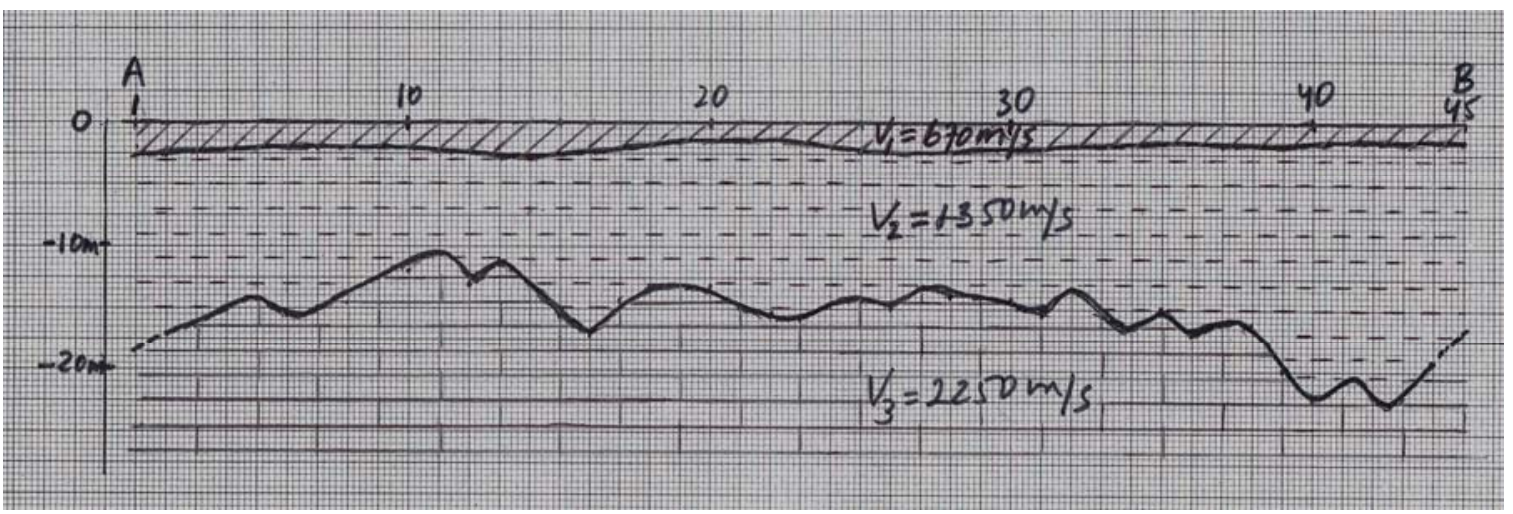

Gambar 3. Penampang kecepatan.

\section{PENUTUP}

Dari analisis data seismik refraksi dengan metode Generalized Reciprocal pada satu lintasan pengukuran yang panjang lintasannya $440 \mathrm{~m}$ dengan 45 posisi geofon, diperoleh informasi mengenai topografi bidang refraktor dibawah lintasan pengukuran, di mana topografi refraktor berundulasi dengan kedalaman bervariaai antara 10,4-22,1 m. dari permukaan Kecepatan rambat gelombang seismik pada refraktor ini adalah $2250 \mathrm{~m} / \mathrm{s}$. Dari data penghitungan fungsi analisis kecepata $\left(\mathrm{t}_{\mathrm{V}}\right)$ untuk harga $X Y 10,20$ dan $30 \mathrm{~m}$, dapat diperkirakan bahwa pada daerah sepanjang lintasan pengukuran seismik tidak terdapat suatu patahan. Harga XYopt hasil perhitungan, 21,2 m, dan hasil observasi $20 \mathrm{~m}$, yang hampir sama, mengindikasikan bahwa sepanjang lintasan pengukuran tidak terdapat lapisan tidak terdeteksi.

\section{DAFTAR PUSTAKA}

Orlowsky, D., Ruter, H., \& Dresen, H. (1998). Combintaion on of common-midpoint refraction seismics with the generalized reciprocal method. Journal of Applied Geophysics, 39 (4), 221235 .

Palmer, D. (1980). An introduction to the the generalized reciprocal method of seismic refraction interpretation. Geophysics, 46, 1508-1518.

Palmer, D. (1980). The Generalized Reciprocal Method of Seimic Refraction Interpretation. Oklahoma: Society of Exploration Geophysicists.

Whiteley, R. J., \& Eccleston, P. J. (2006). Comparison of shallow seismic refraction interpretation methodes for regolith mapping. Paper presented at $18^{\text {th }}$ ASEG Geophysical Conference \& Exhibition, Juli 2006. 